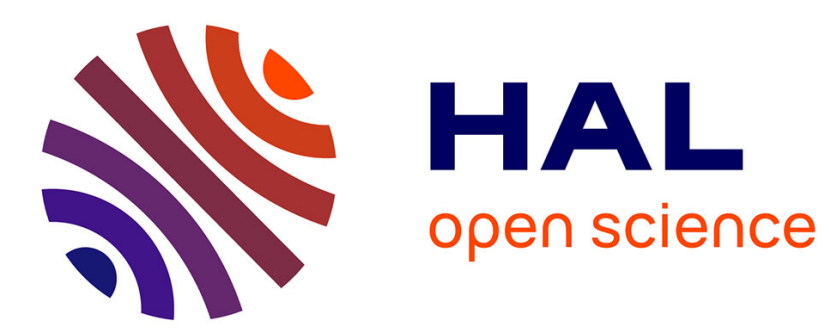

\title{
Effect of torrefaction intensity on the flow properties of lignocellulosic biomass powders
}

John Pachón-Morales, Julien Colin, Floran Pierre, François Puel, Patrick Perre

\section{- To cite this version: \\ John Pachón-Morales, Julien Colin, Floran Pierre, François Puel, Patrick Perre. Effect of torrefaction intensity on the flow properties of lignocellulosic biomass powders. Biomass and Bioenergy, 2019, 120, pp.301-312. 10.1016/j.biombioe.2018.11.017 . hal-01959291}

\section{HAL Id: hal-01959291 \\ https://hal.science/hal-01959291}

Submitted on 18 Dec 2018

HAL is a multi-disciplinary open access archive for the deposit and dissemination of scientific research documents, whether they are published or not. The documents may come from teaching and research institutions in France or abroad, or from public or private research centers.
L'archive ouverte pluridisciplinaire HAL, est destinée au dépôt et à la diffusion de documents scientifiques de niveau recherche, publiés ou non, émanant des établissements d'enseignement et de recherche français ou étrangers, des laboratoires publics ou privés. 
To cite this article: J. PACHON-MORALES, J. COLIN, F. PIERRE, F. PUEL and P. PERRE, (2019) Effect of torrefaction intensity on the flow properties of lignocellulosic biomass powders, Biomass and Bioenergy 120, 301-312 https://doi.org/10.1016/j.biombioe.2018.11.017

\section{Effect of torrefaction intensity on the flow properties of}

\section{lignocellulosic biomass powders.}

John Pachón-Morales ${ }^{a}$, Julien Colina ${ }^{a}$,Floran Pierre ${ }^{a}$, François Puel ${ }^{\mathrm{a}}$ and Patrick Perré ${ }^{* a}$

aLGPM, Laboratoire de Génie des Procédés et Matériaux, CentraleSupélec, Université Paris-Saclay, 3 rue Joliot Curie, 91192

Gif-sur-Yvette, France

\section{ABSTRACT}

Flowability characterization of milled lignocellulosic biomass is essential for developing viable conveying, storing and handling solutions for gasification processes. This study investigated the effect of torrefaction on particles size and shape obtained after grinding and on flow properties of pulverized wood. Spruce and poplar samples with six torrefaction intensities were knife-milled to obtain biomass powders. Particles size and shape distribution were assessed using a morphological particle size analyser and flowability parameters were determined with a ring shear tester. A more intense treatment produces finer, rounder and more regular particles. Simultaneously, a gradual shifting was observed from a cohesive behaviour for native biomass to a nearly free flowing behaviour for the most intensively treated samples. The trends in flowability cannot be explained by the size reduction nor the increase of distribution width. Instead, the explanation lies in the reduction of shape factor and the sharpness of particle surfaces for treated samples. However, all observations are consistent with the loss of resilience of treated wood. From our results, it is clear that torrefaction, in addition to its interest on reduction of energy consumption of grinding, should also be considered as a pre-treatment step allowing to modify the flow behaviour of biomass powders.

Keywords: BtL, torrefaction, particles size and shape, lignocellulosic biomass, flowability

\footnotetext{
${ }^{*}$ Corresponding author. Tel.: +33 (0) 175316679.

E-mail address: john.pachon@centralesupelec.fr (J. Pachón-Morales) patrick.perre@centralesupelec.fr (P. Perré)
} 


\section{INTRODUCTION}

Effective use of biomass gains worldwide attention as a feedstock for production of biofuels likely to reduce greenhouse gas emissions and dependence from petroleum-based energy resources. After the first generation of biofuels, that consumes edible products, a second generation using the lignocellulosic part of plants - such as wood - started to be developed at the industrial scale for lignocellulosic ethanol, but still needs development to produce biomass-to-liquid (BtL) fuels. One thermo-chemical BtL route includes a gasification process followed by a Fischer-Tropsch synthesis [1]. This thermochemical process requires a supply of ground biomass in the form of powder for three main reasons: i) to ease the conveying of the raw material along the processing chain, ii) to optimize its injection into the gasifier and iii) to increase the chemical reactivity of the biomass [2]. Grinding is then essential to obtain biomass powders meeting optimal conditions for gasification. However, due to its fibrous and resilient structure, grinding of native lignocellulosic biomass is an energyintensive process. Therefore, a pre-treatment step, such as torrefaction, is needed to improve the process.

Torrefaction is a thermochemical treatment operating at temperatures in the range 200 to $300{ }^{\circ} \mathrm{C}$ under atmospheric pressure and in absence of oxygen. The process is traditionally characterised by low heating rates $\left(<50{ }^{\circ} \mathrm{C} \cdot \mathrm{min}^{-1}\right)$ and by a relatively long reactor residence time (typically higher than 30 minutes) [3]. The resulting product is intermediate between wood and charcoal and exhibits several advantages when compared to the original material such as an increased energy density [4], a decreased hygroscopicity, a dimensional stabilization [4], an increased resistance to biological decay [5], a loss of mechanical resilience [6], etc. Several studies have shown the efficiency of heat treatment on easing biomass grinding. A reduction of $80-90 \%$ of the power consumption needed for grinding torrefied biomass can be attained in comparison with raw biomass [3]. This means a power consumption similar to that of coal. Previous research found a linear inverse correlation between the average particle diameter after grinding and the torrefaction temperature for wood chips and logging residues [7]. Pierre et al. developed an original impact device to evaluate the grindability of torrefied biomass [8]. The authors showed an energy consumption reduction of $86 \%$ for oak torrefied to $38 \%$ of mass loss and a reduction of $99 \%$ for pine torrefied to $45 \%$ of mass loss.

Currently, transport and handling of biomass powders are a key obstacle for the cost-competitive production of second-generation biofuels. Indeed, creating a steady flow of the biomass particles out of the storage equipment is a significant issue for biomass processing and conversion. From industrial experience, the 
most common cause of failure in continuous biomass valorisation facilities is feeding problems into the reactors [9].

Notwithstanding the frequent occurrence of handling problems, there is still a relatively poor knowledge of the flow properties of biomass materials [10]. More research is therefore needed in this field to ensure the sustainability of the supply chain [11]. This includes a better understanding of the combined effect of torrefaction and grinding parameters and the effects of particles shape and size distributions on powder flow properties. Flowability is often characterised through the unconfined yield strength $\left(\sigma_{c}\right)$ which indicates the tendency of a bulk solid to form a cohesive arch in a hopper and to create ratholes in process equipment [12]. Following the procedure described in Section 2.5, unconfined yield strength is obtained from the Mohr analysis of the yield locus (failure strength against load stress) of a granular material.

Regarding particle size, studies for coal-biomass systems have shown that bigger particles tend to reduce the bulk solids yield strength compared to finer particles [13]. Several models have been proposed to relate the particle size properties to the bulk unconfined yield strength. So far, only inverse relationships between the particle size and the unconfined yield strength, whichever the mechanism considered, are proposed (Van der Waals Forces, capillary forces, elastic fracture, plastic-elastic fracture) [14-16]. These models have typically the following general expression [12]:

$$
\sigma_{C}=\frac{K}{d_{p}^{n}}
$$

Where $\sigma_{c}$ represents the unconfined yield strength, $K$ and $n$ stand for constants dependent on the material properties and $d_{p}$ is a particle size descriptor. Experiments conducted on flame retardant powders [17] showed that samples cohesion decrease with increase of particle size. Similar conclusions for black soybean powders, where fine fractions were reported as cohesive, were made by [18]. Rohilla [19] concluded that there exists a particular particle size after which intermolecular forces become larger than weight forces, which triggered a decrease on flowability of fly ash samples.

The lack of suitable standard methods for measuring and classifying particle shapes, the heterogeneity of shapes and the fibrous nature of biomass particles makes it difficult to characterize the effects of these parameters on the flow properties [9]. Yet, several studies assessed the effects of shape on unconfined yield strength and found that irregular shapes tend to increase the cohesive strength between particles. According to [12], two key parameters influence the strength of a bulk powder system: the number of contacts per adjacent 
particles and the direction of these contacts relative to the centroid axis between adjacent particles. In the case of irregular particles, more effective contacts exist between particles and this situation can therefore increase yield locus values, resulting in a more cohesive behaviour. Several studies have shown that bridging properties of chipped solid biofuels are mainly controlled by the shape and the size of the particles [20]. A high proportion of hooked or long and thin particles increased the bridging tendency. Similar results were obtained by [21] for ground pine and spruce. Hann [22] found that powders with narrow particle size distributions had better flowability and that bulk solids with rounded edges resulted in a greater unconfined yield strength. Particle shape is also essential when studying the specific surface area that governs mass and heat transfer phenomena during gasification [23-25].

Even though particle size and shape are likely to have the greatest impact on powder flow properties, few studies have evaluated powder flow in relation to both, particle size and shape, especially regarding biomass powders, and even less knowledge is available about the effect of heat treatment on particles properties.

Previous works have reported the effect of torrefaction intensity as measured by the global mass loss (ML) on the flowability of biomass powders [26]: a direct relationship between the $M L$ and the flowability factor was observed. The current work investigates the effect of different torrefaction intensities on the flow properties of knife-milled biomass (spruce and poplar), and assesses the relations between:

- The torrefaction mass loss and the particle size and shape obtained after grinding

- $\quad$ The particle size and shape and the granular material flow behaviour.

The results of this research are summarized as expressions between torrefaction operating conditions and physical properties and flowability of biomass particles. They are very useful in optimizing the BtL chain as they allow the compromise between energy loss due to torrefaction, grinding energy and flowability to be clearly assessed.

\section{MATERIALS AND METHODS}

\subsection{Biomass preparation}

A hardwood and a softwood species have been considered for this study. Poplar was chosen as hardwood (Populus euro-americana Koster) as it is a promising forest energy crop, namely due to its fast growth 
in temperate climates. The development of poplar genotypes with improved yield, higher pest resistance, increased site adaptability and easy vegetative propagation has made poplar a commercially valuable energy crop $[27,28]$. The poplar tree selected for the present study came from a forest located in La Suippe valley in Auménancourt-le-Petit (France). Spruce (Picea abies), a softwood species, is another potential candidate to be used in BtL chains, mainly because of its intensive current use in the forestry industry. A spruce tree coming from a plantation in the Le Châtaignier forest in Riotord (France) was selected. Both trees were chopped and cut in boards that were subsequently dried.

The sample size was chosen to fulfil several constraints such as the amount required for flowability tests $\left(30 \mathrm{~cm}^{3}\right.$ of powder needed), the grinding capacity of the grinder (maximum length) and the homogeneity of the heat treatment (small thickness). The size of each individual wood chip was thus fixed to $20 \times 20 \times 3 \mathrm{~mm}^{3}$. Each sample of Table 1 consists of 32 chips of this size. The basic densities (oven-dry mass over saturated volume) are $311 \pm 9 \mathrm{~kg} / \mathrm{m}^{3}$ and $330 \pm 10 \mathrm{~kg} / \mathrm{m}^{3}$, for untreated poplar and spruce respectively. The respective growth ring widths are $14 \mathrm{~mm}$ and $2.85 \mathrm{~mm}$. As it is well-known that wood properties present little changes in the longitudinal direction, all samples were collected along a single board to reduce the intra-tree variability. To further average the remaining variability and obtain twin samples, the 32 wood chips of each sample were selected following a recurrent stepped scheme along the board [26].

Table 1. Torrefaction conditions and global mass loss for the 14 samples studied.

\begin{tabular}{|c|c|c|c|}
\hline \multirow[t]{2}{*}{ Torrefaction temperature $\left({ }^{\circ} \mathrm{C}\right)$} & \multirow[t]{2}{*}{$\begin{array}{c}\text { Duration of } \\
\text { torrefaction }(h)\end{array}$} & \multicolumn{2}{|c|}{$\begin{array}{l}\text { Global mass loss, ML } \\
\quad(\%)\end{array}$} \\
\hline & & Poplar & Spruce \\
\hline \multicolumn{2}{|l|}{ Untreated } & 0 & 0 \\
\hline 220 & 1 & 2.8 & 2.0 \\
\hline 220 & 5 & 8.0 & 4.7 \\
\hline 250 & 1 & 12.0 & 7.1 \\
\hline 250 & 5 & 21.3 & 14.4 \\
\hline 280 & 1 & 25.2 & 18.7 \\
\hline 280 & 5 & 47.3 & 38.1 \\
\hline
\end{tabular}

In agreement with previous findings of $[6,29,30]$, the mass loss values confirm the lower thermal resilience of poplar compared to spruce (Table 1). This is mainly explained by the lower resistance of hardwood hemicelluloses and lignins to heat treatment [31,32]. 


\subsection{Torrefaction}

A batch torrefaction furnace specifically developed in the laboratory was used to treat the samples [33]. The atmosphere of a hermetically closed Memmert UFP400 chamber is controlled by sweeping a nitrogen flow (5 L.min $\left.{ }^{-1}\right)$ to reduce the oxygen content, thereby avoiding oxidation and ignition. In all cases, the oxygen level, as measured at the gas outlet, remained below $1.5 \%$. A powerful fan inside the chamber ensures an efficient heat transfer either to heat-up the sample or to limit thermal overshot due to exothermic reactions. The gas temperature was measured nearby the samples using a K-thermocouple.

A total of six treatments were performed at 220,250 and $280{ }^{\circ} \mathrm{C}$ for 1 or 5 hours with the following protocol: (i) heating from room temperature at a rate of $5^{\circ} \mathrm{C} \mathrm{min}^{-1}$ up to $100{ }^{\circ} \mathrm{C}$ (ii) plateau at $100{ }^{\circ} \mathrm{C}$ for 30 minutes to remove the residual bound water (iii) heating at a rate of $5{ }^{\circ} \mathrm{C} \mathrm{min}^{-1}$ until the treatment temperature. (iv) plateau at the treatment temperature for the desired duration and (v) cooling down thanks to thermal losses and an increased nitrogen flow entering the reactor. Preliminary simulations were performed using a comprehensive computational code to ensure that the treatment duration together with the sample thickness ensures the treatment to be quasi-uniform within the sample [34].

After treatment, samples were weighed to determine the mass loss (ML) due to heat treatment as follows:

$$
M L(\%)=\frac{m_{0}-m_{t}}{m_{0}} \cdot 100
$$

Where, $m_{0}$ and $m_{t}$ are the oven-dry mass before and after torrefaction, respectively. Mass loss is known to be a good indicator of the treatment intensity [4] and has been successfully correlated to several properties of the treated biomass such as energy properties [8] or dimensional changes [6].

\subsection{Grinding procedure}

Heat-treated samples were ground in a M20 IKA laboratory 550W knife miller. An automatic control system was implemented to guarantee the repeatability of the grinding procedure. The rotational speed of the knives (stainless steel cuter M21) was $20000 \mathrm{rpm}$. To avoid any additive heat treatment due to thermal dissipation, several grinding and resting cycles were carried out, up to a total grinding time of 95 seconds. A circulation of cold water inside the grinder jacket further reduced sample heating. 


\subsection{Particle size and shape analysis}

A Sympatec-QICPIC morphological particle size analyser with a M7 lens (measurement ranges from 10 to $10240 \mu \mathrm{m})$ with a GRADIS dispersion and VIBRI feeding units was used in this work [35]. To conduct the test, about $5 \mathrm{~g}$ of wood powder was loaded onto the hopper of the instrument. The size and shape of powders were recorded and analysed using the manufacturer software.

The mean value of the Feret diameters over all orientations of the particle) is used as the magnitude characterizing particles size. The $50^{\text {th }}$ centile of the cumulative volume distributions $\left(\chi_{50}\right)$ was taken as a mean size descriptor of each size distribution. The particle shape was characterised through the circularity, $\psi$ (from 0 to 1), which is defined as the ratio of the perimeter of a circle having the same area as the projected area of a particle to its actual perimeter. A perfect sphere would give $\psi=1$ and the smaller the value of $\psi$, the more irregular is the shape of the particle. Mean values of circularity $\psi_{50}$ were calculated as the $50^{\text {th }}$ centile of the cumulative circularity distributions.

The flow of a polydispersed bulk solid primarily depends on flow properties of the fines fraction [13], the size analysis of particles having a size under $100 \mu \mathrm{m}$ was made for all samples. Hence the sieve fraction of the samples with a size below $100 \mu \mathrm{m}$ was analysed. This fraction was obtained by using a vibratory sieve shaker Retsch AS 200 at a frequency of $60 \mathrm{~Hz}$ for 20 minutes. Particles size and shape were analysed using a M4 lens allowing a better resolution for finer particles in the range from $<1 \mu \mathrm{m}$ to $1700 \mu \mathrm{m}$. The use of this lens needs samples to be fed as a liquid dispersion. Biomass powders were first coloured by means of a 24-hour soaking in a Safranin-O - $10 \%$ ethanol solution to avoid agglomeration, then diluted in $500 \mathrm{~mL}$ of water. This solution was pumped into the LIXELL wet dispersion system. Results presented are the combination of three repeatable tests.

\subsection{Flowability tests}

A RST-XS Schulze ring shear tester was used to assess the flow properties of biomass powders. The ring shear tester is a widely-used device to measure flow properties of powders, including angle of internal friction, wall friction and bulk density. The standard procedure leads to results with low variability [36]. According to this procedure, once the shear cell with the powder sample has been prepared, the maximum normal preshear stress, $\sigma_{\text {pre }}$ is applied on the cell lid. A typical evolution of the shear stress obtained from torque measurements is represented in Figure 1a. The pre-shearing step is carried out up to the attainment of a steady 
state value of shear stress in which the frictional forces between particles are maximum with respect to the applied normal load. At this point the powder attains a well-defined and reproducible state of consolidation corresponding to the top point of the yield locus represented in Figure 1b. This steady state often occurs when the sample volume and thus its bulk density, $\varrho_{b}$, reaches a steady state value at the end of compaction [37]. After the preshearing, the direction of shear is reversed, i. e. the shear stress is reduced to zero. Then, the normal stress is reduced to a value $\sigma_{s b, 1}<\sigma_{p r e}$ and the specimen is sheared until a peak value of shear stress, $\tau_{s h}$ is reached (incipient flow or failure) [10]. The sequence of two steps is repeated with the same $\sigma_{p r e}$ and increasing $\sigma_{s b}$. Finally, a verification point at $\sigma_{s b, 1}$ is made. The $(\sigma, \tau)$ couples obtained at failure are drawn to represent the yield locus corresponding to the consolidation applied as shown in Figure 1b).

A set of three pre-consolidation stresses $\left(\sigma_{p r e}\right)$, considered as representative of the stress range for industrial applications, were tested: 2,5 and $10 \mathrm{kPa}$ [38]. Three shear points at 25, 50 and $75 \%$ of $\sigma_{\text {pre }}$ for each pre-consolidation stress were used to determine the yield locus of each sample. The yield locus curves were regressed from experimental points by a linear regression.

As represented in Figure $1 \mathrm{~b}$ ), the Mohr circle drawn through steady state point and tangent to the yield locus locates the major principal stress $\sigma_{1}$, corresponding to the consolidation applied. The unconfined yield strength is given by the major principal stress passing through the origin and tangent to the yield locus. In Figure 1b), the dashed line passing the origin and tangent to the larger Mohr circle is the effective yield locus. Its angle of inclination with respect to the $\sigma$ axis is the effective angle of internal friction $\phi_{e}$. Yield locus for a non-cohesive granular material passes through the origin, so cohesion, $C$, corresponds to the value of the shear stress where the yield locus intersects with the $\tau$ axis, i.e., at the normal stress $\sigma=0$. By measuring yield loci for different preconsolidation stresses a flow function $\left(\sigma_{c}\right.$ vs. $\left.\sigma_{1}\right)$ can be drawn.

Unconfined yield strength governs the stress holding the material together on a free surface. It is the major principle stress that acts in a direction parallel to the free surface which supports the external forces tending to tear the surface apart [39]. The bigger its value, the higher the stress required to fail or fracture the granular material to initialize the flow. The unconfined yield strength indicates the tendency of a bulk solid to form a cohesive arch in a hopper and form ratholes in process equipment [12]. 
The ratio FFC (flow function coefficient) of consolidation stress to unconfined stress $\left(\sigma_{1} / \sigma_{c}\right)$ is used to quantify the flowability. The larger FFC, the better a bulk solid flows. All properties obtained from the Schulze ring shear tester are usually reported as a function of the major principal stress of consolidation.

a)

b)

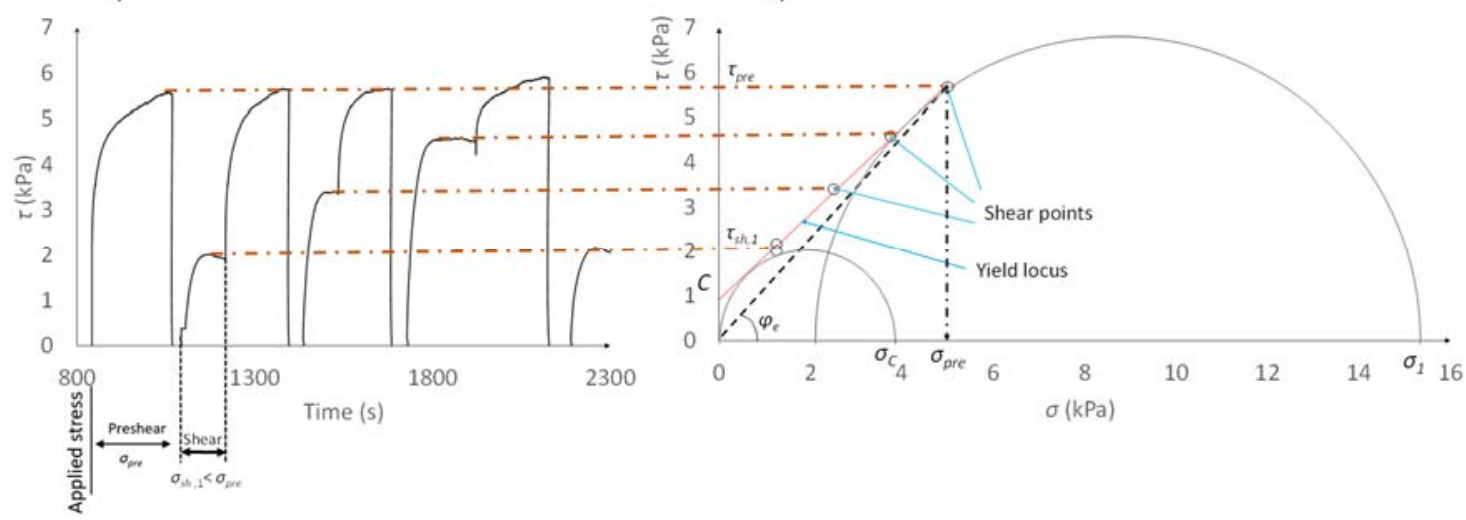

Figure 1. Flow properties determination (Untreated poplar sample, $\sigma_{\text {pre }}=5 \mathrm{kPa}$ ). a). Experimental course of shear stress; b)

yield locus construction and Mohr stress circles defining unconfined yield strength and consolidation stress.

\section{RESULTS}

\subsection{Effect of torrefaction intensity on particle size and shape distributions}

A surface representation (Figure 2) was chosen to represent both the shape factor and the particle size distributions for three degrees of torrefaction: untreated, mildly treated $\left(250{ }^{\circ} \mathrm{C}, 1\right.$ hour $)$ and intensively treated $\left(280^{\circ} \mathrm{C}, 5\right.$ hours). A gradual shifting from large particles with relatively low circularity towards finer particles and higher values of circularity becomes evident when increasing the torrefaction intensity. This reduction of particle size is a direct effect of the loss of resilience [40]. This is also the primarily reason of using torrefaction as pretreatment on the BtL chain: to obtain small and reactive particles at a lower grinding energy cost.

These 2D graphs deserve a deeper analysis of the concomitant changes of size, circularity and peak intensity. For poplar powders, the peak value for circularity changed from $\psi=0.6$ to $\psi=0.75$ (increase of $25 \%$ ) 
from untreated to the most treated samples. For spruce, circularity peak values increased from $\psi=0.55$ to $\psi=0.77$ (increase of $40 \%$ ). This increase of circularity with torrefaction was already observed for pine [7].

From the colour scale, it is also noticeable that, for both species, a spreading of the distributions occurs at increased heat treatment intensity. For poplar, the initial, sharp, peak at $2 \mathrm{~mm}$ evolved progressively towards a wider peak spreading towards smaller and more spherical particles. Spruce presents a different behaviour as two populations gradually appear. The initial peak is slightly shifted towards smaller particles (1800 $\mu \mathrm{m}, 1500 \mu \mathrm{m}$ and $600 \mu \mathrm{m}$, from untreated to $7 \%$ and $38 \%$ of ML) and progressively disappears. Another peak is already visible at $\mathrm{ML}=7.1 \%$ at a mean particle size of ca. $300 \mu \mathrm{m}$. For the most severe treatment $(\mathrm{ML}=$ $38.1 \%$ ) the initial peak almost disappeared and the second peak represents a large part of the power volume, with smaller (ca. $100 \mu \mathrm{m})$ and round particles $(\psi=0.77)$.
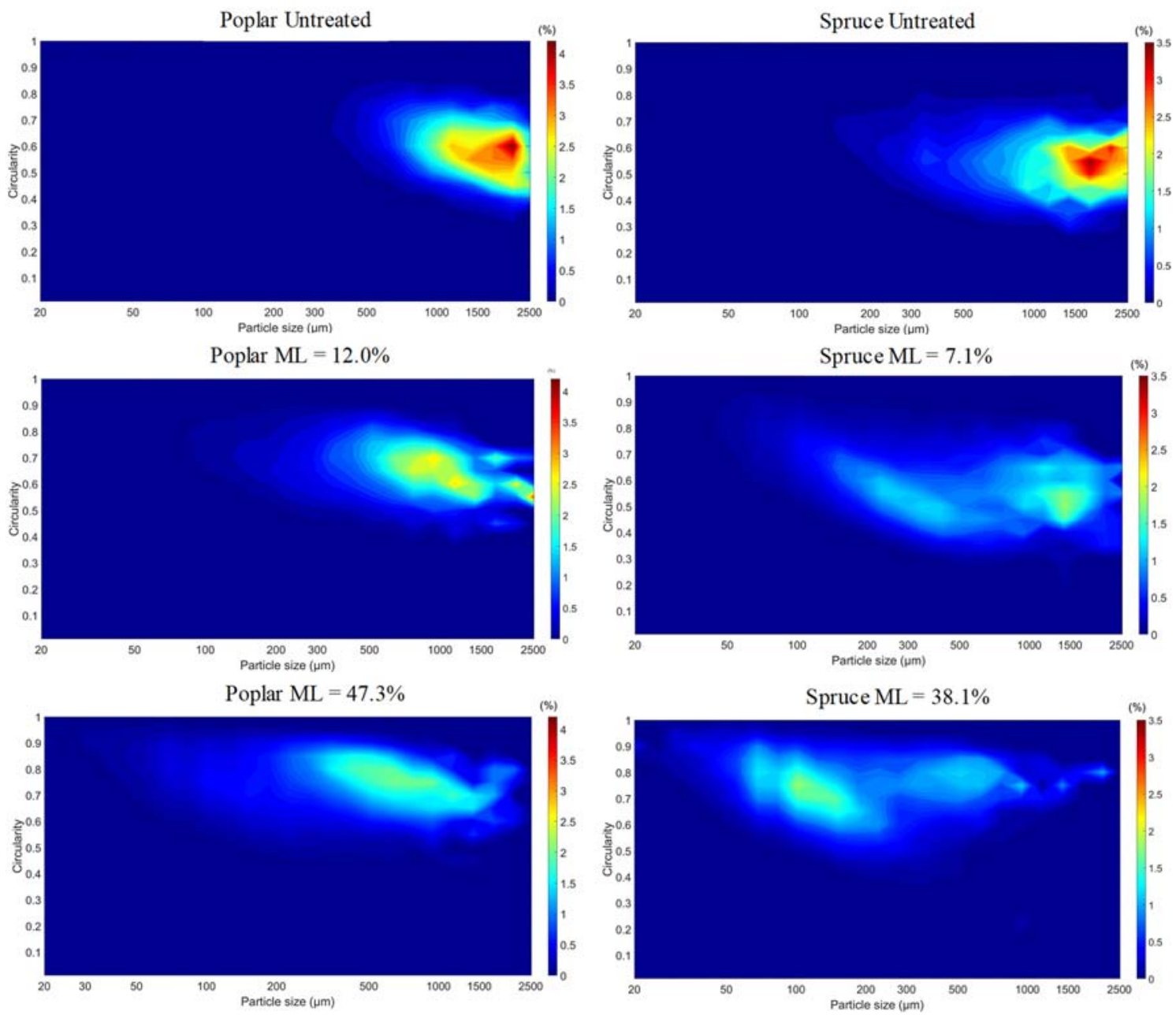
Figure 2. Influence of torrefaction intensity on circularity and size distributions for spruce and poplar powders. The colour scale indicates the volume fraction of each size and shape range and varies between the same values regardless of the torrefaction intensity for each species.

Figure 3 (top) presents the cumulative volume particle size distribution (PSD) for poplar and spruce. This synthetic representation allows the size reduction at increasing heat treatment intensities to be quantified. The trends reported in this figure confirm literature data $[2,7,41]$. In the case of poplar, for the highest values of mass loss, the cumulative distributions tend to overlap. This indicates that a plateau in particle size seems to be reached after a certain treatment intensity. Again, spruce presents a different behaviour, as a significant shifting of the particle size distribution towards finer particles is still observed for the most severe treatments.

These trends are confirmed by the analysis of the fines fraction (Figure 3, bottom). For poplar, the fines fraction presents a plateau at ca. $7 \%$ of the total particle volume and the three most severe treatments ( $21 \%$ to $47 \%$ of mass loss) are very close. On the contrary, a large increase of the fines fraction is observed for $\mathrm{ML}=38 \%$ : almost $40 \%$ of the particle volume. It is also obvious that the particle size distribution continues to shift towards small particles. 
POPLAR

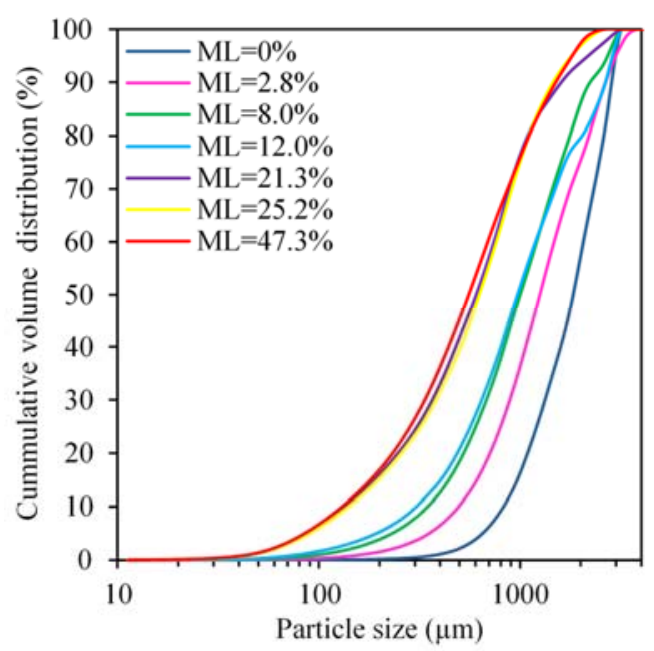

SPRUCE

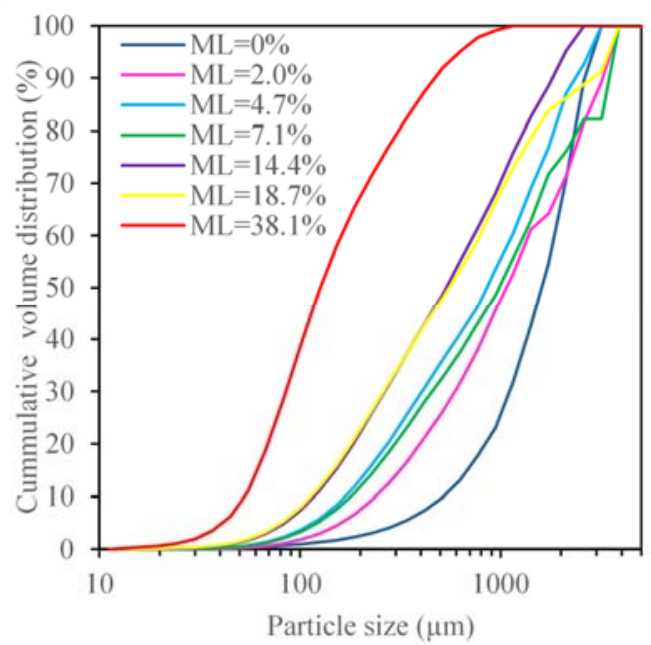

Fines fraction

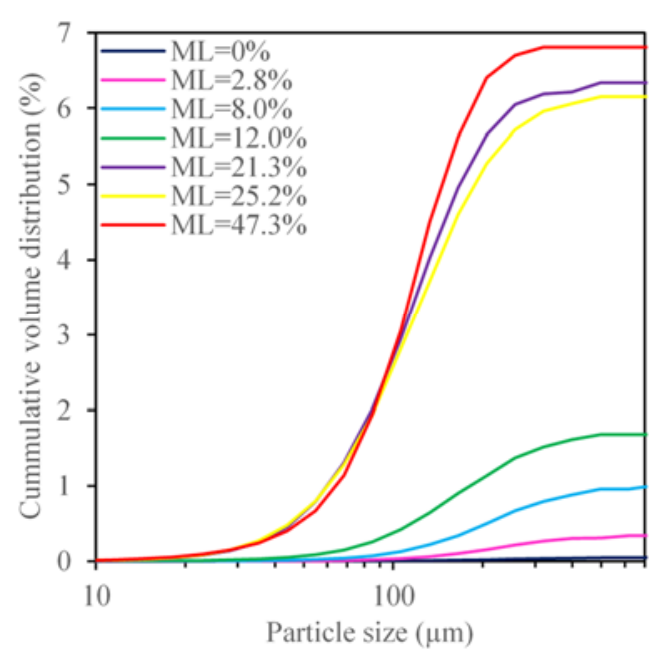

Figure 3. Influence of torrefaction intensity (Mass Loss ML) on PSD: whole sample (top) and fines fraction (bottom) 

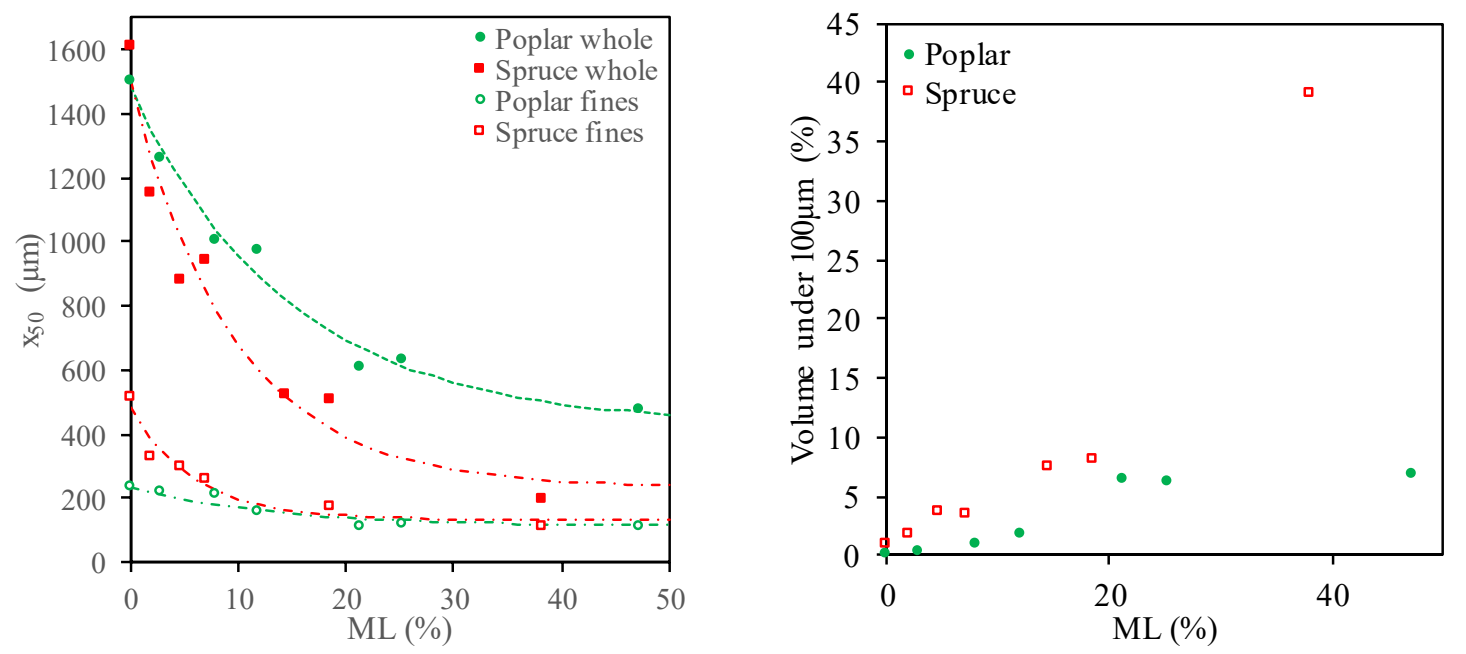

Figure 4. Effect of torrefaction intensity on the mean particle size (left) and volume of fines (right) of poplar and spruce powders.

As synthetic indicator of the particle size reduction, the $50^{\text {th }}$ centile $\left(x_{50}\right)$ of the particles size distribution was plotted as a function of $M L$ in Figure 4. For the entire particle samples and for the fines fractions as well. Exponential expressions of the form $x_{50}=a \cdot\left(b+e^{-c \cdot M L}\right)$ were also fitted from these experimental data. The fitted parameters are presented in Table 2. These models imply an asymptotic behaviour whose limit at "infinite torrefaction intensity" equals $427 \mu \mathrm{m}$ for poplar and $226 \mu \mathrm{m}$ for spruce.

Table 2. Parameters of the exponential regressions of the form $x_{50}=a \cdot[b+\exp (-c \cdot M L)]$ for the mean particle size after grinding as a function of $M L$.

\begin{tabular}{llll}
\hline Sample & $a$ & $b$ & $c$ \\
\hline Poplar whole samples & 1067 & 0.40 & 0.069 \\
Poplar fines & 347.4 & 0.38 & 0.170 \\
Spruce whole samples & 1258 & 0.18 & 0.104 \\
Spruce fines & 120.7 & 0.91 & 0.069 \\
\hline
\end{tabular}

The general trend clearly confirms the loss of resilience at increasing treatment intensity. A similar behaviour is observed for the two species. Yet, larger particles are obtained for poplar compared to spruce at similar torrefaction intensity. For spruce, the particles size is reduced by $88 \%$ for untreated to severely treated wood $(M L=38 \%)$. The reduction is only by $68 \%$ for poplar. A higher effect of thermal treatment on the particle size reduction is therefore evident for spruce, even though the $M L$ presents an opposite trend (lower values for spruce than for poplar for given torrefaction conditions). 
This result is quite surprising as the alteration of lignins and hemicelluloses by heat treatment explains the increase of cell wall brittleness. The native lignins of conifers are essentially constituted of guaiacyl (G) units together with a low proportion of $p$-hydroxyphenyl $(\mathrm{H})$ units (except in compression wood rich in $\mathrm{H}$ units). Along with the $\mathrm{G}$ units and traces of $\mathrm{H}$ units, the lignins of deciduous trees are constituted of syringyl (S) units. The proportion of resistant bonds in native lignins increases with the frequency of $\mathrm{G}$ and $\mathrm{H}$ units whereas $\mathrm{S}$ units are mostly involved in weaker $\beta-\mathrm{O}-4$ linkages. From this molecular point of view, poplar resilience should therefore be more deeply altered by heat treatment than spruce.

As the observation regarding PSD depicts an opposite trend, the explanation is likely to rely on the difference in anatomical structure. Poplar is a pore-diffuse hardwood species which presents two levels of porosity: vessels and cell lumen (fibers and parenchyma cells). This heterogeneity creates various possible fracture pathways of the tissue that permits large particles to be formed. On the contrary, spruce is made of tracheids for $95 \%$ of its volume. Consequently, the formation of particles necessarily required fractures at this unique pore scale. This produces smaller particles, namely single tracheids or fractions of tracheids and a significant proportion of fines particle even at low treatment intensity. Obviously, this trend is stronger at higher ML levels, due to its effect in weakening the cell wall. The consequence on the proportion of fines (particle $<100 \mu \mathrm{m}$ ) is impressive: whereas both species depict a linear increase with mass loss, the proportion of fines increases up to $40 \%$ for spruce, against $8 \%$ for poplar.

Finally, two synthetic indicators, in addition to the $50^{\text {th }}$ centile values, are proposed to quantify the spreading of the distributions, the span criteria: $S_{X}$ for size and $S_{\psi}$ for circularity, calculated from the respective $90^{\text {th }}$ and $10^{\text {th }}$ centiles of cumulative distributions as follows:

$$
\begin{aligned}
& S_{x}=\frac{x_{90}-x_{10}}{x_{90}+x_{10}} \\
& S_{\psi}=\frac{\psi_{90}-\psi_{10}}{\psi_{90}+\psi_{10}}
\end{aligned}
$$

Where $x_{90}$ and $x_{10}$ stand for the $90^{\text {th }}$ and $10^{\text {th }}$ centiles of the PSD and $\psi_{90}$ and $\psi_{10}$ represent the $90^{\text {th }}$ and $10^{\text {th }}$ centiles of circularity distributions. 
These criteria are reported in Table 3. The span of the particle size distribution tends to increase with the increase of torrefaction intensity. This trend is clearer for poplar than for spruce. However, for both species, an important increase from torrefied to untreated samples is observed ( $+50 \%$ for spruce and $+19 \%$ for poplar). Powders of torrefied wood exhibit a more polydispersed population with smaller sizes than powders of native wood. The span of circularity distributions did not depict any clear tendency.

Table 3. Ground samples properties: Global mass loss, mean particle size, mean circularity and span values.

\begin{tabular}{|c|c|c|c|c|c|c|c|c|c|c|c|}
\hline \multirow{2}{*}{$\begin{array}{l}\text { Torrefaction } \\
\text { temperature } \\
\quad\left({ }^{\circ} \mathrm{C}\right)\end{array}$} & \multirow{2}{*}{$\begin{array}{l}\text { Torrefaction } \\
\text { duration (h) }\end{array}$} & \multicolumn{5}{|c|}{ Poplar } & \multicolumn{5}{|c|}{ Spruce } \\
\hline & & $\begin{array}{l}M L \\
(\%) \\
\end{array}$ & $\begin{array}{l}x_{50} \\
(\mu \mathrm{m}) \\
\end{array}$ & $S_{x}$ & $\psi_{50}$ & $S_{\psi}$ & $\begin{array}{l}M L \\
(\%) \\
\end{array}$ & $x_{50}(\mu \mathrm{m})$ & $S_{x}$ & $\psi_{50}$ & $S_{\psi}$ \\
\hline \multicolumn{2}{|c|}{ Untreated } & 0 & 1504 & 0.56 & 0.57 & 0.24 & 0 & 1611 & 0.67 & 0.52 & 0.26 \\
\hline 220 & 1 & 2.8 & 1261 & 0.69 & 0.60 & 0.22 & 2.0 & 1153 & 0.86 & 0.53 & 0.29 \\
\hline 220 & 5 & 8.0 & 1006 & 0.73 & 0.62 & 0.20 & 4.7 & 881 & 0.87 & 0.55 & 0.28 \\
\hline 250 & 1 & 12.0 & 975 & 0.79 & 0.63 & 0.21 & 7.1 & 940 & 0.90 & 0.54 & 0.29 \\
\hline 250 & 5 & 21.3 & 606 & 0.84 & 0.70 & 0.19 & 14.4 & 520 & 0.86 & 0.59 & 0.28 \\
\hline 280 & 1 & 25.2 & 628 & 0.82 & 0.68 & 0.20 & 18.7 & 504 & 0.88 & 0.58 & 0.30 \\
\hline 280 & 5 & 47.3 & 475 & 0.84 & 0.72 & 0.21 & 38.1 & 192 & 0.80 & 0.72 & 0.21 \\
\hline
\end{tabular}

\subsection{Effect of torrefaction intensity on flow properties of biomass powders.}

Flow functions presented in Figure 5 give information about the different flowability regimes by considering the ratio between the unconfined yield strength and the major consolidation stress (Jenike, 1964). A FFC value below 1 indicates a not flowing behaviour, while a value of 4 represents the transition from cohesive to easy-flowing. Above 10, the powder is considered as free-flowing. The graphs obtained for our samples depict a clear effect of the heat treatment intensity on the evolution of these flow functions, either for spruce or for poplar.

For poplar, the curve obtained for the powder of native biomass is close to the line FFC $=4$. It is therefore at the transition between cohesive and easy-flowing behaviour. Starting from this value, a gradual and regular shift of the curves towards higher values of FFC is evident. The most intense treatment lies close to $F F C=10$, which is the transition between easy-flowing and free-flowing. 
Spruce samples depict the same trend, but over a larger amplitude. Untreated biomass is at the middle of the cohesive zone, whereas the curve obtained for the most intense treatment (ML $=38 \%$ ) the FFC $=10$ boundary. One has also to notice that the progression observed for spruce is not as regular as for poplar.
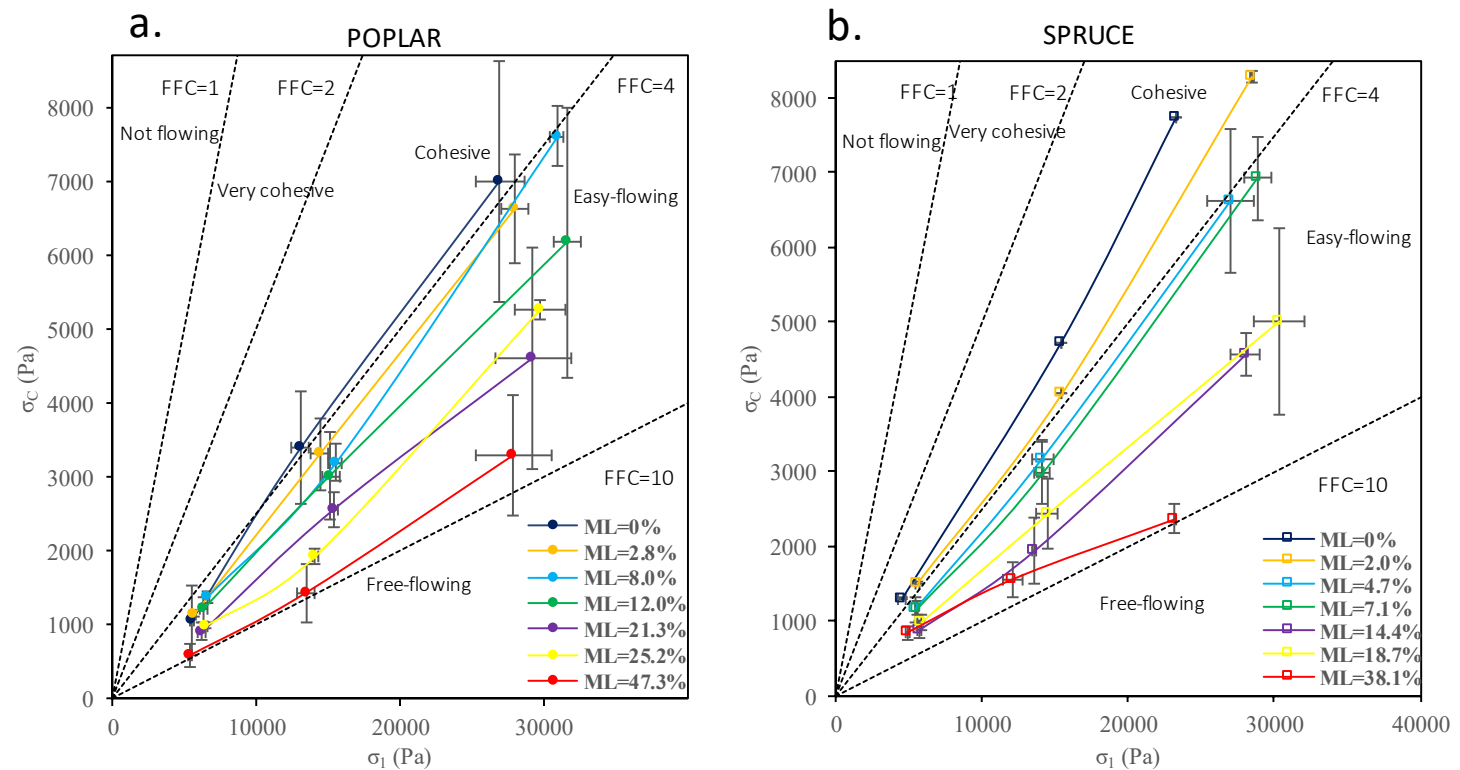

Figure 5. Effect of torrefaction intensity (ML) on flow properties for a. poplar and b. spruce powders $\left(\sigma_{\text {pre }}=5 \mathrm{kPa}\right)$.

These trends encouraged us to use the mass loss due to heat treatment $(M L)$ as indicator of the flowability of biomass powder. As stated in this introduction, this parameter already proved to be an excellent synthetic indicator [4] for other biomass energy and mechanic properties. To that purpose, the value of FFC obtained with a pre-consolidation stress of $5 \mathrm{kPa}$ was plotted as a function of $M L$ for both species (Figure 6). Except one point for spruce, the quasi-perfect linear relationship obtained is remarkable. Similar trends were found for the other consolidation stresses studied (see the Annexe). Both species showed a quantitatively similar trend. Flowability factor increased by $105 \%$ and $118 \%$ for poplar and spruce, respectively, from the untreated to the most intensively treated samples. Mass loss could then be used in industry for practically assessing the powder flowability of biomass powder under consolidation, since its ease of obtaining. In addition, both species are on the same line. By removing the singular point found for spruce at $\mathrm{ML}=14.4 \%$, a unique, linear, expression can be proposed to predict the effect of mass loss on flowability, valid for all the consolidation stresses studied $\left(r^{2}=0.80\right)$ :

$$
\frac{F F C}{F F C_{\text {untreated }}}=1+2.81 \mathrm{ML}
$$


In this expression, that should be considered has one of the major outcomes of the present work, $F F C_{\text {untreated }}$ represents the flowability factor (dimensionless) of powder from native biomass and $M L$ is the mass loss due to heat-treatment $(\mathrm{kg} / \mathrm{kg})$. As a conclusion from this trend it can be seen that, in contrast with raw biomass, torrefied wood particles have higher flowability, which will ease the injection of pulverized biomass into boilers in gasification units.

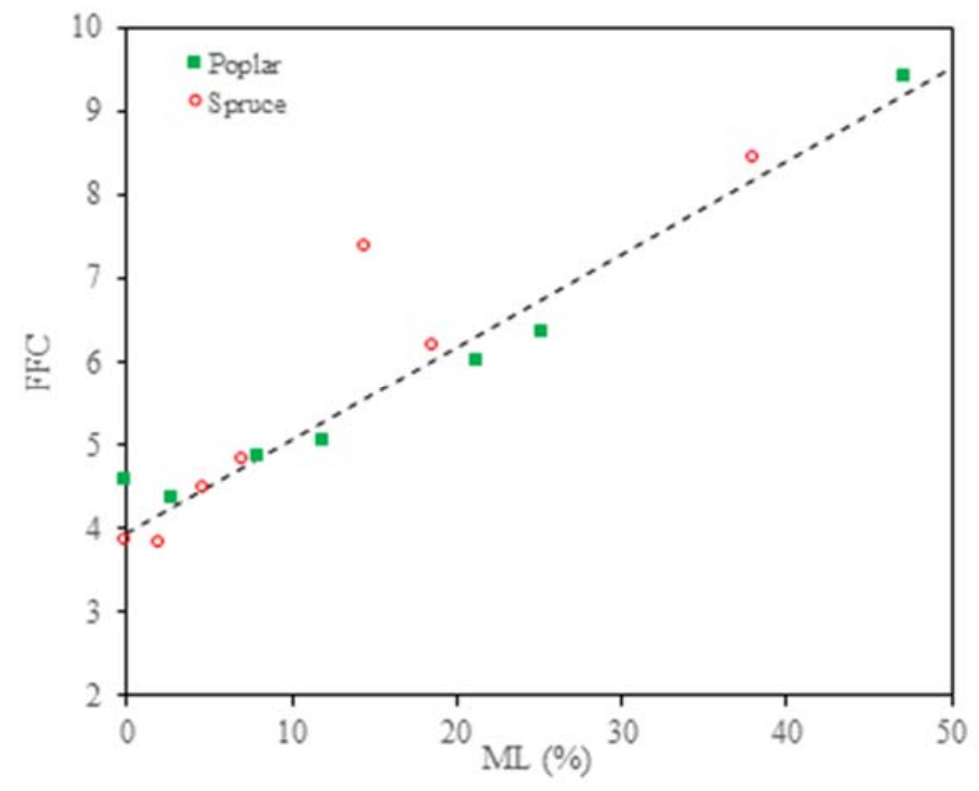

Figure 6. Effect of the torrefaction intensity on the flowability factor of poplar and spruce powders (for clarity purposes only values at $\sigma_{\text {pre }}=5 \mathrm{kPa}$ are presented).

\section{DISCUSSION ON THE COMBINED EFFECTS OF}

\section{PARTICLE SIZE/SHAPE AND TREATMENT INTENSITY.}

The previous results told us that:

1. The treatment intensity allows smaller and more spherical particles to be produced by grinding,

2. The flowability of particles obtained from heat-treated wood increases significantly and linearly with mass loss. 
It is therefore likely to go further in the explanation and to investigate if the evolution of the flowability can be explained by the particle size and shape. To that purpose, Figure 7 represent some of flow properties as a function of particle size and circularity. Either for poplar or for spruce, the unconfined yield strength increases with particle size and decreases with circularity. Similar trends were found for the other consolidations stresses studied and presented in Annexe. The third plot (Figure 7c) represents the value of FFC obtained with a preconsolidation stress of $5 \mathrm{kPa}$ in a 3D plot, which depicts the concomitant change of size and circularity. This last plot summarises the effect of heat-treatment on flowability:

- Heat-treatment reduces the mean particle size and increases the circularity,

- The cumulated of these two trends increases the powder flowability.

As stated in previous works [37,42-44], for a given shape, flow properties tend to improve with mean particle size. As particles become finer, the van der Waals forces of attraction between them increase relatively because of their larger specific surface area $\left(\mathrm{m}^{2} / \mathrm{g}\right)$. During shear cell testing, there is a larger number of particleparticle contacts on the shear failure plane for a powder comprised of smaller particles (Hou \& Calvin, 2008). Consequently, the total area of contact is larger for smaller particles. At the same time, particles with less mass are subject to lower gravitational forces.

The net result of these effects is the shifting of the yield locus towards higher stresses and thus, a larger value unconfined yield strength and smaller flowability, which is opposite to the clear trends observed in the present work. Other effects are therefore likely to counterbalance the sole effect of particle size. In addition to the mean size, the width of size distribution might be involved. As reported in [38], qualitatively speaking, flowability of bulk solids having the same median, $x_{50}$, increases with decreasing width of the particle distribution. Again, this observation would produce an effect opposite to our observations: Table 2 tells us that the intensity of heat-treatment increases the width of the particle distribution, yet the flowability increases. Polydispersity effects were also studied by [37] for a mixture of coarse and fine lactose particles. The larger the percentage of the finer component, the more the yield locus was shifted towards higher stresses and the smaller the flowability. Interestingly, this trend was not observed for torrefied biomass powders.

Additional explanations have therefore to be found. The flowability improvement could then be triggered by the change in the shape factor of the particles. Generally, when considering coarse particles, smooth, spherical particles flow better than rough, sharp-edged, non-spherical particles. This has been 
demonstrated for different kinds of granular materials: [45] found that the higher the mean circularity the lower the cohesion for glass beads samples. Deviation of particle shape from sphericity led to higher angles of repose for microcrystalline cellulose [46] and higher compressibility in lactose powders [44]. [47] also concluded that there is an increase in the flowability of bulk solids when there is an increase in the shape factor of the particles.

a.

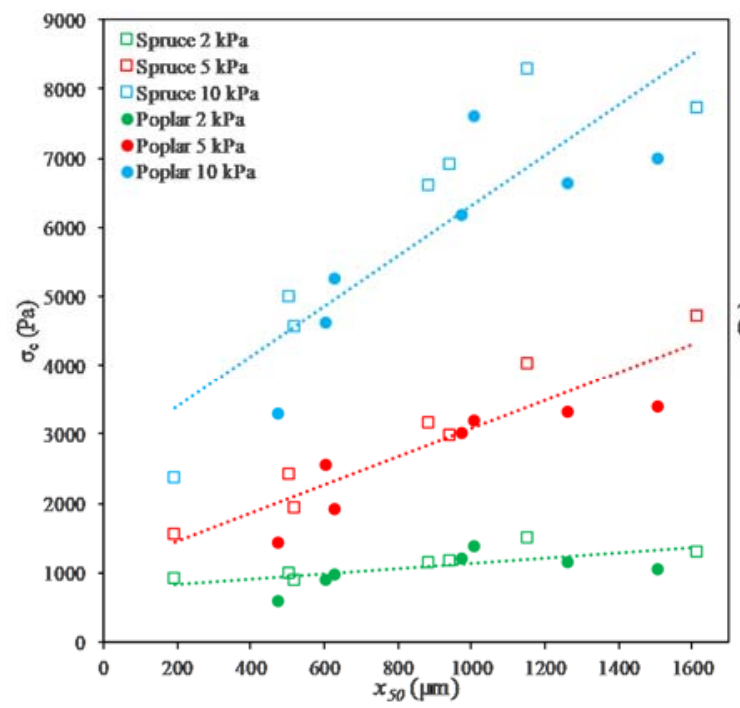

b.

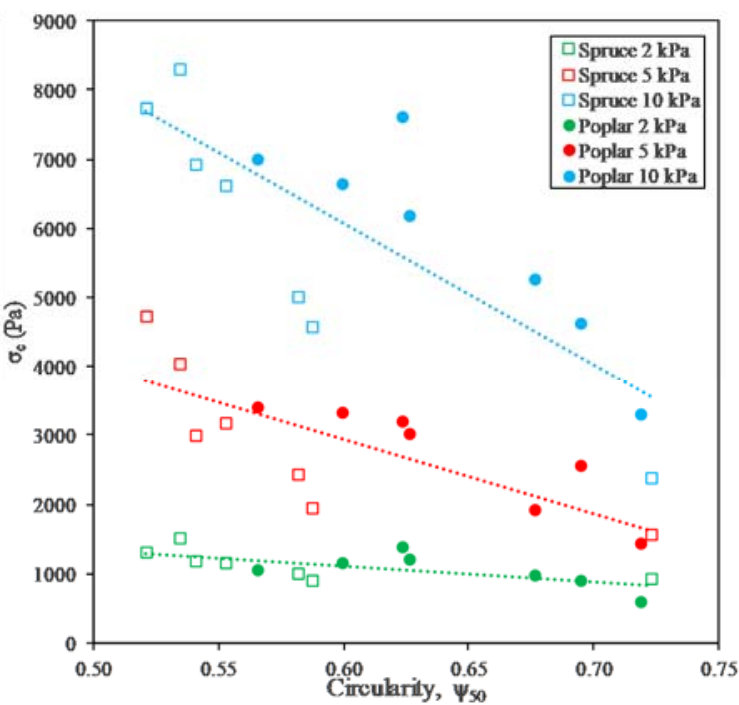

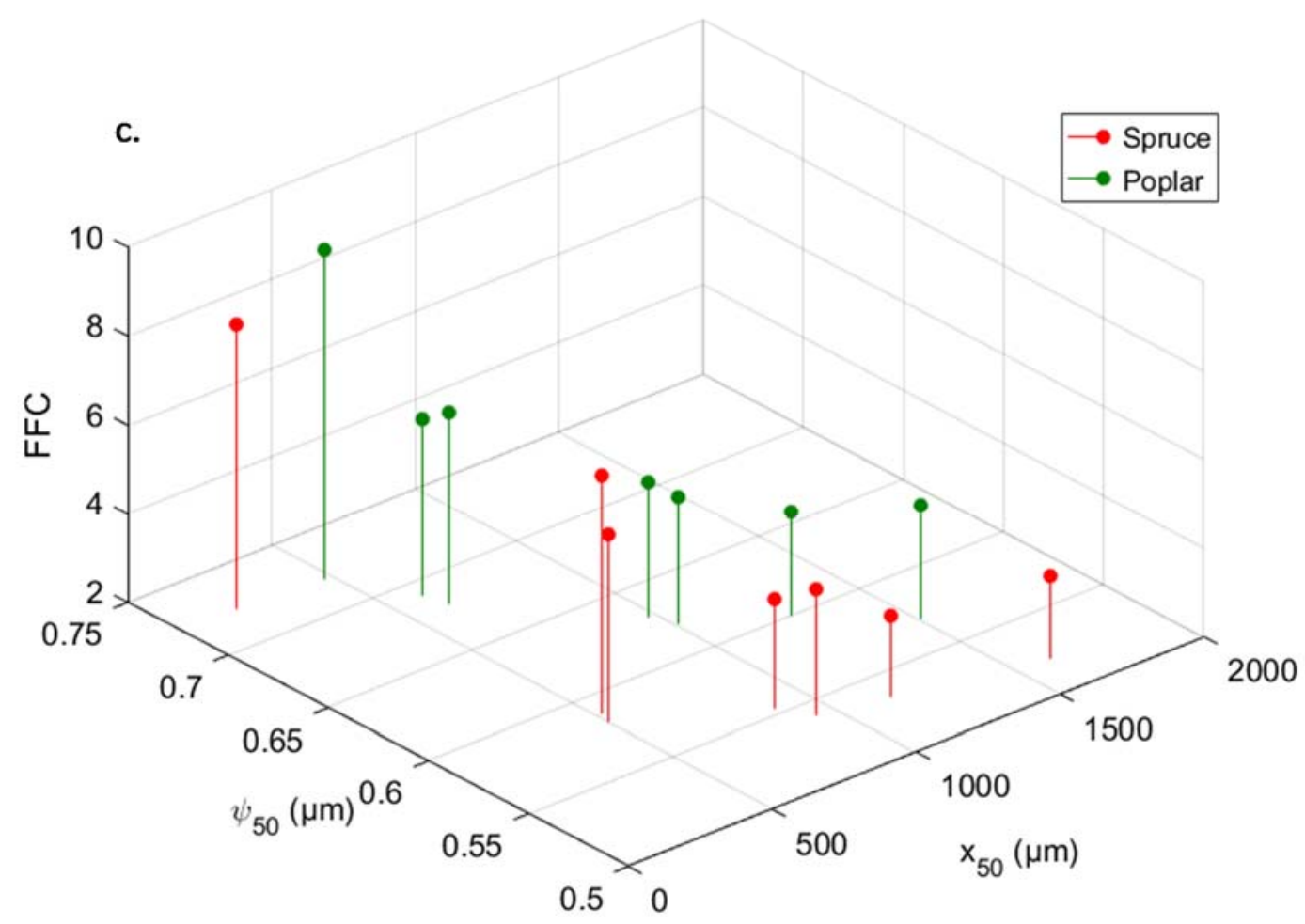

Figure 7. Effect of particle size and shape on flow properties for poplar and spruce powders: $a$. b. Unconfined yield strength, $c$. flowability factor $\left(\sigma_{\text {pre }}=5 \mathrm{kPa}\right)$. 
For untreated biomass powders, the steric repulsion and frictional forces that are a consequence of the particle geometry lead to a greater extent of inter-particulate friction and locking. Hence, yield loci are shifted to bigger values when compared with torrefied samples, resulting in a decreased flowability. Similar findings have been reported previously by [48] for pharmaceutical powders, where some flowability properties such as the internal angle of friction where primarily influenced by particle shape and relatively independent of particle size.

Another effect to take into consideration, regarding polydisperse systems such as biomass powders, is the lubricant effect of fine particles on coarser ones. Flow agents prevent particle surface from direct contact, reducing inter-particle adhesion forces and improving flowability. In the case of intensively torrefied powders, where very fine-grained powders were obtained and therefore the adhesive force between the biggest particles would be reduced due to the increased inter-particle distance caused by very small covering particles acting as lubricant. However, flow agent particles must be sufficiently small in order to limit the adhesive forces of the flow agent particles themselves. The bigger shifting of flow functions from cohesive to free-flowing behaviour shown in Figure 5 for spruce powders could be seen as a result of the higher amount of very fine particles compared to poplar samples. Since flow agents are often based on nanosized particles, a granulometric analysis at nanometric resolution would be useful for further validation of this hypothesis.

Besides size and shape modifications, torrefaction is likely to alter the surface properties of biomass powders as well. The hydrophobic nature of torrefied samples could affect flow properties trough the electrostatic forces in two ways. Firstly, as the presence of bound water lowers the electrical resistivity, raw samples (which tend to capture moisture more easily) will tend to dissipate the electrostatic charges better. Secondly, as indicated in previous research [49], the electrostatic properties of the particles are directly related to the surface functional group chemistry: hydrophobic groups accumulate greater quantities of charge than hydrophilic groups. All of this would mean that, all other parameters being the same, torrefied samples are more likely to present flow problems linked to charge build-up. However, flow problems induced by accumulation of electrostatic charges are mainly to be expected in free surface flows of fine powders or when the powder is in contact with non-conductive surfaces. In closed systems, as the ring shear tester, the effect of electric charges could thus be mainly neglected. As the samples were oven-dried prior to the flowability measurements, the formation of liquid bridges at the particle scale (which could increase cohesion) was also neglected. 
SEM images of particles were grabbed for spruce and poplar for different treatment intensities using a FEI Quanta electron microscope (Figure 8). When the treatment intensity increases, a decrease of particles length for a relatively similar width can be observed. This means a reduction of particles elongation which generally goes hand-in-hand with a circularity increase, as measured by the granulometric analysis made. The changes of circularity are very gradual, especially at low treatment intensities (Table 3). They become significant for intense treatments (for poplar, average circularity increased by $+26 \%$ compared to the raw biomass). SEM images are rather intended to show tearing, pulling-out and breaking profiles, that are affected by torrefaction, in addition to the shape changes (that are better evaluated statistically by the granulometric analysis). For untreated samples, the fibrous and resilient behaviour of wood produces irregular needle-like particles, with tearing and pull-out profiles. Pulled-out fibres together with rather elongated particles certainly promote particle agglomeration, which is likely to reduce powder flowability. On the contrary, sharp breaking surfaces are observed for torrefied samples. These observations confirm the conclusions of both shape and size analysis and are in good agreement with those done by [50,51]. The effects of loss of resilience on the particle shape becomes thus evident, from native to severely treated biomass. 

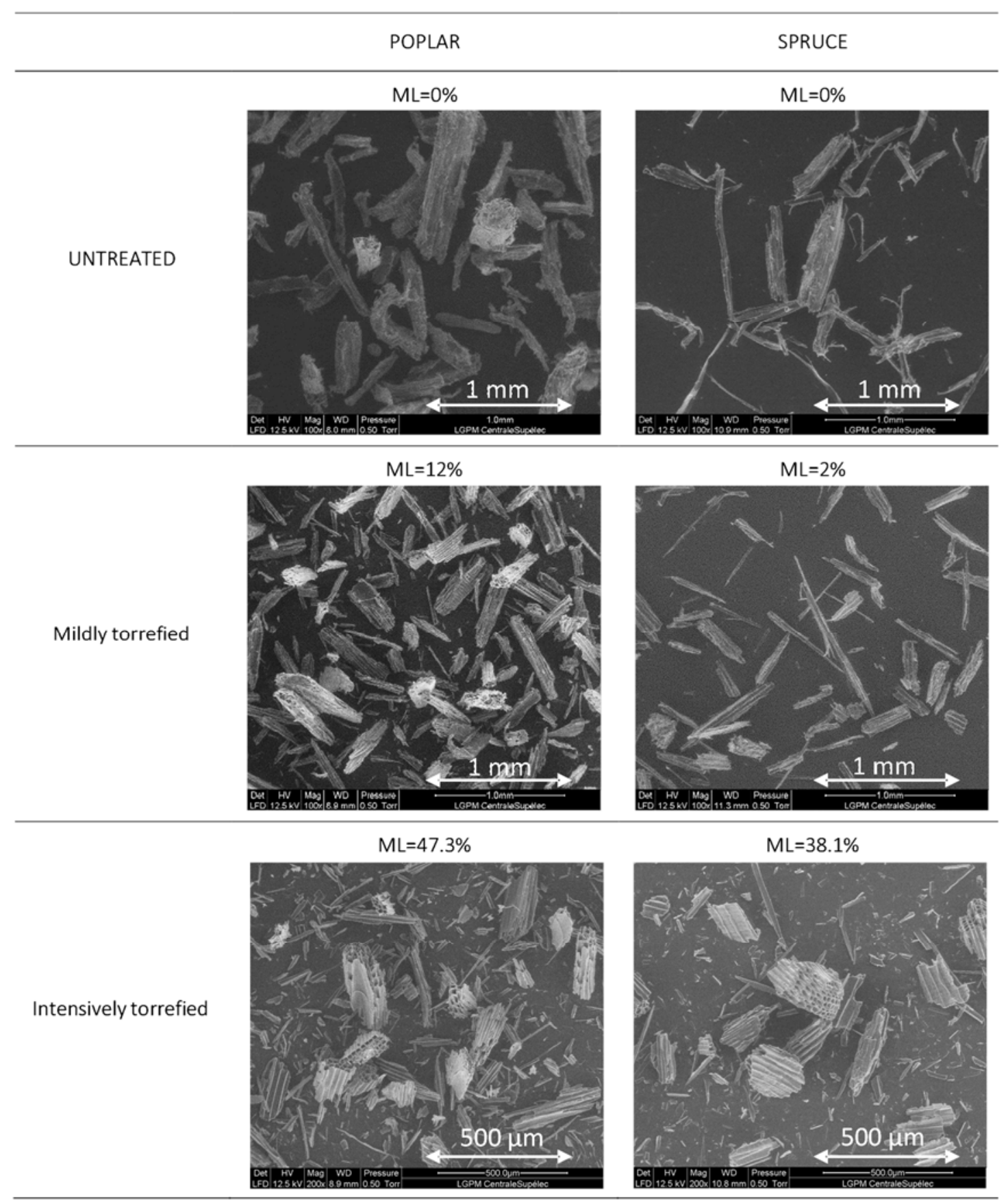

Figure 8. Scanning Electronic Microscopic images for untreated and torrefied spruce and poplar powders.

As a conclusion of this discussion, we proved that the increase in flowability of wood powder with heat-treatment intensity is in complete opposition with the reduction of mean particle size or the increase in distribution width. Therefore, different effects should be involved to counterbalance the effect of particle size and to explain the clear improvement of flowability with heat treatment. Two major effects were pointed out. 
Both are tied to the loss of resilience of the fibrous behaviour of native biomass: i) the reduction of the shape factor (higher particle circularity) and ii) the much higher regular and convex shape of particles.

\section{CONCLUSIONS}

The study, focused on two wood species, poplar and spruce, investigated the effect of torrefaction on the particles size and shape obtained after grinding and on the flow properties of milled wood. Overall, a gradual shifting of the particle size and shape distributions towards finer and rounder particles was observed when increasing treatment intensity. At the same time, a significant improvement of the flowability with torrefaction intensity was also clearly exhibited. Milled biomass gradually shifted from a cohesive character for the native samples to a nearly free flowing behaviour for the most intensively treated samples. Considering these observations, a unique linear expression between torrefaction intensity and flowability factor was proposed for the two-species studied here.

Finally, we proved that the concomitant evolution of particle sizes and distribution width and flowability parameters are not consistent as smaller particles should exhibit lower flowability. Indeed, the increase of flowability is mostly due to rounder particles with sharp surfaces of treated biomass compared to long and irregular needle-like particles obtained for native biomass. Both consequences, flowability improvement and size/shape factor reduction, are therefore explained by the same effect: the loss of resilience of the fibrous structure of raw wood by heat-treatment.

\section{Acknowledgements}

The support of the Ministère de l'Enseignement Supérieur et de la Recherche (France) is gratefully acknowledged. 


\section{APPENDIX: Additional flow properties: angles of}

\section{friction, cohesion and bulk density.}

The friction angles are parameters related to the inter-particle friction of bulk solids and are one of the most used parameters to characterize their handling behaviour. The angle of internal friction $\phi_{\text {lin }}$ is obtained from the slope of the linearized yield locus and the slope of the effective yield locus represents the effective angle of friction $\phi_{e}[38]$.

Cohesion characterizes the shear stress at yield under zero normal stress, i.e. the intersection of the yield locus with the ordinate. Bulk density is defined as the ratio of the mass of an amount of bulk solid to its volume. It is usually function of the consolidation stress. In the Schulze ring shear tester, the bulk density is calculated from the total charged mass of sample and the volume considering the lid displacement for a given consolidation stress [38].

Erreur ! Source du renvoi introuvable. presents the values of the linearized internal angle of friction and the effective angle of internal friction resulting from the Schulze shear cell tests. There is not much difference between the angles for poplar and spruce showing that there is a similar interparticle friction when the two species are compared. Variations of angles between the different degrees of torrefaction intensity are not very clear and are often below the standard variation of the set of measurements (around $1^{\circ}$ ). These results are comparable with those obtained by [52] for poplar chips $\left(\varphi_{\text {lin }} \approx 46^{\circ}\right)$.

Regarding cohesion, it follows the same trend than the unconfined yield strength: a more cohesive behaviour is observed for the untreated powders then a gradual decrease follows until the minimal value for the most intensively torrefied samples. Like the other flow properties, cohesion is strongly dependent on the consolidation stress: with increasing consolidation stresses the yield locus skewed towards greater shear stresses because of the greater shear stress necessary to initiate flow. When the two-wood species are compared, relatively more cohesive behaviour was found for the spruce samples than for poplar powders.

Table 1. Flow properties for milled poplar and spruce at different torrefaction intensities.

\begin{tabular}{|c|c|c|c|c|c|c|c|c|c|c|c|c|c|c|c|}
\hline & & \multicolumn{7}{|c|}{ POPLAR } & \multicolumn{7}{|c|}{ SPRUCE } \\
\hline & \multirow[b]{2}{*}{$\sigma_{p r e}(\mathrm{kPa})$} & \multicolumn{7}{|c|}{ ML (\%) } & & \multicolumn{6}{|c|}{ ML (\%) } \\
\hline & & 0.0 & 2.8 & 8.0 & 12.0 & 21.3 & 25.2 & 47.3 & 0.0 & 11.4 & 14.7 & 17.4 & 25.4 & 30.9 & 46.5 \\
\hline \multirow{3}{*}{$\begin{array}{l}\text { Unconfined yield } \\
\text { strength }(\mathrm{kPa})\end{array}$} & 2 & 1060 & 1148 & 1375 & 1207 & 906 & 983 & 582 & 1299 & 1508 & 1151 & 1174 & 884 & 988 & 912 \\
\hline & 5 & 3393 & 3310 & 3190 & 3011 & 2554 & 1926 & 1430 & 4717 & 4042 & 3172 & 2979 & 1945 & 2426 & 1557 \\
\hline & 10 & 6992 & 6635 & 7607 & 6171 & 4610 & 5267 & 3293 & 7729 & 8277 & 6619 & 6925 & 4570 & 5006 & 2370 \\
\hline
\end{tabular}




\begin{tabular}{|c|c|c|c|c|c|c|c|c|c|c|c|c|c|c|c|}
\hline \multirow{3}{*}{$\begin{array}{c}\text { Flowability factor } \\
\text { FFC }\end{array}$} & 2 & 5.2 & 5.0 & 4.8 & 5.3 & 6.9 & 6.6 & 9.2 & 3.5 & 3.7 & 4.9 & 4.7 & 6.5 & 6.0 & 5.8 \\
\hline & 5 & 4.6 & 4.4 & 4.9 & 5.0 & 6.0 & 6.3 & 9.4 & 3.9 & 3.8 & 4.5 & 4.8 & 7.4 & 6.2 & 8.4 \\
\hline & 10 & 3.9 & 4.2 & 4.1 & 5.1 & 6.3 & 5.7 & 8.5 & 3.0 & 3.4 & 4.1 & 4.2 & 6.2 & 6.3 & 11.0 \\
\hline \multirow{3}{*}{$\begin{array}{l}\text { Major consolidation } \\
\text { stress }(\mathrm{kPa})\end{array}$} & 2 & 5490 & 5692 & 6564 & 6360 & 6231 & 6449 & 5355 & 4517 & 5544 & 5473 & 5550 & 5759 & 5814 & 5273 \\
\hline & 5 & 13906 & $\begin{array}{r}14407 \\
\end{array}$ & 15507 & 15172 & 15352 & 14087 & 13458 & 15437 & 15437 & 14160 & 14127 & 13629 & 14450 & 12937 \\
\hline & 10 & 26978 & 27981 & 30957 & 31709 & 29251 & 29737 & 27927 & 23359 & 28432 & 27003 & 28881 & 28046 & 30395 & 25861 \\
\hline \multirow{3}{*}{$\begin{array}{c}\text { Angle of } \\
\text { internal friction, } \varphi_{\text {lin }}\left({ }^{\circ}\right)\end{array}$} & 2 & 43.8 & 47.4 & 47.2 & 48.0 & 47.7 & 47.4 & 45.3 & 39.0 & 41.8 & 43.5 & 45.1 & 46.5 & 46.9 & 44.7 \\
\hline & 5 & 42.2 & 44.5 & 48.0 & 47.4 & 46.5 & 47.3 & 44.2 & 40.0 & 46.2 & 44.4 & 44.5 & 46.5 & 46.0 & 44.3 \\
\hline & 10 & 43.4 & 44.9 & 46.2 & 45.2 & 45.2 & 45.9 & 46.2 & 39.6 & 44.3 & 43.5 & 45.2 & 45.4 & 47.2 & 44.0 \\
\hline \multirow{3}{*}{$\begin{array}{l}\text { Effective angle } \\
\text { of friction, } \varphi_{t}\left({ }^{\circ}\right)\end{array}$} & 2 & 48.1 & 51.6 & 51.6 & 51.8 & 50.7 & 50.5 & 47.6 & 46.2 & 48.2 & 47.8 & 49.2 & 49.7 & 50.5 & 48.4 \\
\hline & 5 & 48.2 & 49.6 & 52.3 & 51.5 & 50.0 & 50.4 & 46.5 & 47.6 & 51.9 & 49.4 & 49.1 & 49.5 & 49.5 & 46.8 \\
\hline & 10 & 49.3 & 50.1 & 51.5 & 50.3 & 48.5 & 49.6 & 48.6 & 47.9 & 51.0 & 49.1 & 50.4 & 48.9 & 50.6 & 46.0 \\
\hline \multirow{3}{*}{ Cohesion $(\mathrm{kPa})$} & 2 & 226 & 225 & 269 & 232 & 175 & 192 & 120 & 310 & 337 & 232 & 244 & 176 & 195 & 190 \\
\hline & 5 & 752 & 692 & 612 & 466 & 508 & 452 & 302 & 1099 & 650 & 665 & 625 & 390 & 493 & 327 \\
\hline & 10 & 1510 & 1385 & 1530 & 1515 & 944 & 1067 & 662 & 1819 & 1742 & 1415 & 1428 & 937 & 980 & 503 \\
\hline \multirow{3}{*}{ Bulk density $(\mathrm{kg} / \mathrm{m} 3)$} & 2 & 152 & 164 & 180 & 180 & 221 & 211 & 221 & 153 & 153 & 174 & 174 & 217 & 221 & 243 \\
\hline & 5 & 152 & 176 & 189 & 187 & 231 & 218 & 224 & 146 & 162 & 188 & 187 & 222 & 232 & 255 \\
\hline & 10 & 165 & 181 & 196 & 195 & 238 & 228 & 227 & 188 & 177 & 198 & 198 & 233 & 237 & 266 \\
\hline
\end{tabular}

Bulk density was found to be directly dependent on the torrefaction intensity of the samples and the consolidation stress applied. Most intensively treated samples trigger denser powders after grinding that untreated ones. This is due to the reduction of both inter- and intra-particle voids generated after grinding with the reduction of particle size. This behaviour agrees with the observations by Mani et al [2]. The increase of bulk density with torrefaction intensity is important: an average of $43 \%$ is gained for the most intensively torrefied poplar sample with respect to the untreated sample. For spruce an average increase in bulk density of $58 \%$ was observed.

\section{REFERENCES}

[1] P. McKendry, Energy production from biomass (part 3): Gasification technologies, Bioresour. Technol. 83 (2002) 55-63. doi:10.1016/S0960-8524(01)00120-1.

[2] S. Mani, L.G. Tabil, S. Sokhansanj, Grinding performance and physical properties of wheat and barley straws, corn stover and switchgrass, Biomass and Bioenergy. 27 (2004) 339-352. doi:10.1016/j.biombioe.2004.03.007.

[3] P.C. a Bergman, a R. Boersma, R.W.R. Zwart, J.H. a Kiel, Torrefaction for biomass co-firing in existing coal-fired power stations, Energy Res. Cent. Netherlands ECN ECNC05013. (2005) 71. doi:ECN-C-05-013.

[4] G. Almeida, J.O. Brito, P. Perré, Alterations in energy properties of eucalyptus wood and bark subjected to torrefaction: The potential of mass loss as a synthetic indicator, Bioresour. Technol. 101 (2010) 9778-9784. doi:10.1016/j.biortech.2010.07.026.

[5] R. Hosseinpourpia, C. Mai, Mode of action of brown rot decay resistance of thermally modified wood: Resistance to Fenton's reagent, Holzforschung. 70 (2016) 691-697. doi:10.1515/hf-2015-0141. 
[6] G. Almeida, D.V.B. Santos, P. Perré, Mild pyrolysis of fast-growing wood species (Caribbean pine and Rose gum): Dimensional changes predicted by the global mass loss, Biomass and Bioenergy. 70 (2014) 407-415. doi:10.1016/j.biombioe.2014.07.028.

[7] M. Phanphanich, S. Mani, Impact of torrefaction on the grindability and fuel characteristics of forest biomass, Bioresour. Technol. 102 (2011) 1246-1253. doi:10.1016/j.biortech.2010.08.028.

[8] F. Pierre, G. Almeida, F. Huber, P. Jacquin, P. Perr??, An original impact device for biomass characterisation: Results obtained for spruce and poplar at different moisture contents, Wood Sci. Technol. 47 (2013) 537-555. doi:10.1007/s00226-012-0512-9.

[9] J. Dai, H. Cui, J.R. Grace, Biomass feeding for thermochemical reactors, Prog. Energy Combust. Sci. 38 (2012) 716-736. doi:10.1016/j.pecs.2012.04.002.

[10] F. Miccio, D. Barletta, M. Poletto, Flow properties and arching behavior of biomass particulate solids, Powder Technol. 235 (2013) 312-321. doi:10.1016/j.powtec.2012.10.047.

[11] Ram $\tilde{A}-$ rez-G $\tilde{A}^{3} m e z$, Research needs on biomass characterization to prevent handling problems and hazards in industry, Part. Sci. Technol. 34 (2016) 432-441. doi:10.1080/02726351.2016.1138262.

[12] K. Johanson, Effect of particle shape on unconfined yield strength, Powder Technol. 194 (2009) 246251. doi:10.1016/j.powtec.2009.05.004.

[13] M. Zulfiqar, B. Moghtaderi, T.F. Wall, Flow properties of biomass and coal blends, Fuel Process. Technol. 87 (2006) 281-288. doi:10.1016/j.fuproc.2004.10.007.

[14] O. Molerus, The role of science in particle technology, Powder Technol. 122 (2002) 156-167. doi:10.1016/S0032-5910(01)00412-0.

[15] H. Rumpf, Particle Technology, Part. Technol. Ser. (1975). doi:10.1007/978-94-011-7944-7.

[16] D.W. SPECHT, Caking of Granular Materials: an Experimental and Theoretical Study, (2006) 127.

[17] E. Abdullah, D. Geldart, The use of bulk density measurments as a flowability, Powder Technol. 102 (1999) 151-165. doi:10.1017/CBO9781107415324.004.

[18] Y.J. Lee, W.B. Yoon, Flow behavior and hopper design for black soybean powders by particle size, J. Food Eng. 144 (2015) 10-19. doi:10.1016/j.jfoodeng.2014.07.005. 
[19] L. Rohilla, V. Garg, S.S. Mallick, G. Setia, An experimental investigation on the effect of particle size into the flowability of fly ash, Powder Technol. 330 (2018) 164-173. doi:10.1016/j.powtec.2018.02.013.

[20] J.E. Mattsson, P.D. Kofman, Method and apparatus for measuring the tendency of solid biofuels to bridge over openings, Biomass and Bioenergy. 22 (2002) 179-185. doi:10.1016/S0961-9534(01)000678.

[21] S. Paulrud, J.E. Mattsson, C. Nilsson, Particle and handling characteristics of wood fuel powder: Effects of different mills, Fuel Process. Technol. 76 (2002) 23-39. doi:10.1016/S0378-3820(02)00008-5.

[22] D. Hann, J. Stražišar, Influence of Particle Size Distribution, Moisture Content, and Particle Shape on the Flow Properties of Bulk Solids, Instrum. Sci. Technol. 35 (2007) 571-584. doi:10.1080/10739140701540453.

[23] H. Lu, E. Ip, J. Scott, P. Foster, M. Vickers, L.L. Baxter, Effects of particle shape and size on devolatilization of biomass particle, Fuel. 89 (2010) 1156-1168. doi:10.1016/j.fuel.2008.10.023.

[24] H. Thunman, B. Leckner, F. Niklasson, F. Johnsson, Combustion of wood particles - A particle model for Eulerian calculations, Combust. Flame. 129 (2002) 30-46. doi:10.1016/S0010-2180(01)00371-6.

[25] R.K. Jalan, V.K. Srivastava, 99/02102 Studies on pyrolysis of a single biomass cylindrical pellet kinetic and heat transfer effects Jalan, R. K. and Srivastava, V. K. Energy Convers. Manage., 1999, 40, (5), 467-494, Fuel Energy Abstr. 40 (1999) 215. doi:10.1016/S0140-6701(99)97872-4.

[26] J. Pachón-Morales, J. Colin, F. Pierre, T. Champavert, F. Puel, P. Perré, Flowability of lignocellusic biomass powders: Influence of torrefaction intensity, EPJ Web Conf. 140 (2017). doi:10.1051/epjconf/201714013017.

[27] Y.H. Jung, H.J. Cho, J.S. Lee, E.W. Noh, O.K. Park, K.H. Kim, Evaluation of a transgenic poplar as a potential biomass crop for biofuel production, Bioresour. Technol. 129 (2013) 639-641. doi:10.1016/j.biortech.2012.12.074.

[28] D. Dickmann, Poplar culture in North America, NRC Research Press, 2001.

[29] D.P. Kamdem, A. Pizzi, A. Jermannaud, Durability of heat-treated wood, (n.d.). doi:10.1007/s00107001-0261-1. 
[30] F. Avat, Contribution à l' étude des traitements thermiques du bois jusqu 'à $300^{\circ} \mathrm{C}$ : Transformations chimiques et caractérisations physico-chimiques To cite this version : HAL Id : tel-00831249, (2013).

[31] V. Repellin, A. Govin, M. Rolland, R. Guyonnet, Modelling anhydrous weight loss of wood chips during torrefaction in a pilot kiln, Biomass and Bioenergy. 34 (2010) 602-609. doi:10.1016/j.biombioe.2010.01.002.

[32] M.J. Prins, K.J. Ptasinski, F.J.J.G. Janssen, Torrefaction of wood. Part 2. Analysis of products, J. Anal. Appl. Pyrolysis. 77 (2006) 35-40. doi:10.1016/j.jaap.2006.01.001.

[33] J. Colin, Séchage en continu du bois énergie comme moyen de conditionnement en vue de sa conservation thermochimique: approches expérimentale et numérique, AgroParisTech, 2011. https://pastel.archives-ouvertes.fr/pastel-00861231.

[34] P. Perré, R. Rémond, I. Turner, A comprehensive dual-scale wood torrefaction model: Application to the analysis of thermal run-away in industrial heat treatment processes, Int. J. Heat Mass Transf. 64 (2013) 838-849. doi:10.1016/j.ijheatmasstransfer.2013.03.066.

[35] Sympatec, QICPIC GmbH, (2018). https://www.sympatec.com/en/particlemeasurement/sensors/dynamic-image-analysis/qicpic/ (accessed July 11, 2018).

[36] ASTM International, D6773-02: Standard Test Method for Bulk Solids Using Schulze Ring Shear Tester 1, Annu. B. ASTM Stand. (2002) 1-26. doi:10.1520/D6682-08.

[37] D. Schulze, Flow properties of powders and bulk solids (fundamentals), Powder Technol. 65 (2010) $321-333$

[38] D. Schulze, Powders and Bulk Solids, Springer Berlin Heidelberg, Berlin, Heidelberg, 2007. doi:10.1007/978-3-540-73768-1.

[39] A.W. Jenike, Gravity flow of bulk solids, (1961). https://collections.lib.utah.edu/details?id=709033 (accessed July 11, 2018).

[40] F. Pierre, G. Almeida, J. Colin, P. Perré, Reduction of biomass resilience by torrefaction: apparent stiffness during failure (ASF) and specific failure energy (SFE) assessed by a custom impact device, Holzforschung. 71 (2017) 863-872. doi:10.1515/hf-2016-0191. 
[41] M. Himmel, M. Tucker, J. Baker, C. Rivard, K. Oh, K. Grohmann, Comminution of biomass: hammer and knife mills., Proc. 7th Symp. Biotechnol. Fuels Chem. Gatlinburg, Tennessee, 14-17 May, 1985. (1986) 39-58. https://www.cabdirect.org/cabdirect/abstract/19862429390 (accessed July 11, 2018).

[42] H. Lu, X. Guo, Y. Liu, X. Gong, Effect of particle size on flow mode and flow characteristics of pulverized coal, KONA Powder Part. J. (2015). doi:10.14356/kona.2015002.

[43] Y. Liu, X. Guo, H. Lu, X. Gong, An investigation of the effect of particle size on the flow behavior of pulverized coal, Procedia Eng. 102 (2015) 698-713. doi:10.1016/j.proeng.2015.01.170.

[44] X. Fu, D. Huck, L. Makein, B. Armstrong, U. Willen, T. Freeman, Effect of particle shape and size on flow properties of lactose powders, Particuology. 10 (2012) 203-208. doi:10.1016/j.partic.2011.11.003.

[45] C.M. Lewandowski, A Preliminary Investigation Concerning The Effect Of Particle Shape On a Powder's Flow Properties, Eff. Br. Mindfulness Interv. Acute Pain Exp. An Exam. Individ. Differ. 1 (2015) 1-10. doi:10.1017/CBO9781107415324.004.

[46] T. Horio, M. Yasuda, S. Matsusaka, Effect of particle shape on powder flowability of microcrystalline cellulose as determined using the vibration shear tube method, Int. J. Pharm. 473 (2014) 572-578. doi:10.1016/j.ijpharm.2014.07.040.

[47] K. Danjo, K. Kinoshita, K. Kitagawa, K. Iida, H. Sunada, A. Otsuka, Effect of particle shape on the compaction and flow properties of powders., Chem. Pharm. Bull. (Tokyo). 37 (1989) 3070-3073. doi:10.1248/cpb.37.3070.

[48] H.P. Goh, P. Wan, S. Heng, C.V. Liew, Comparative evaluation of powder fl ow parameters with reference to particle size and shape, Int. J. Pharm. 547 (2018) 133-141. doi:10.1016/j.ijpharm.2018.05.059.

[49] K.W. Biegaj, M.G. Rowland, T.M. Lukas, J.Y.Y. Heng, Surface Chemistry and Humidity in Powder Electrostatics: A Comparative Study between Tribocharging and Corona Discharge, ACS Omega. 2 (2017) 1576-1582. doi:10.1021/acsomega.7b00125.

[50] G. Almeida, F. Pierre, L. Murta, P.M.P. Perré, Caractérisation mécanique du produit traité et mise en relation des taux de dégradations avec les propriétés mécaniques, (2009). 
[51] B. Arias, C. Pevida, J. Fermoso, M.G. Plaza, F. Rubiera, J.J. Pis, Influence of torrefaction on the grindability and reactivity of woody biomass, Fuel Process. Technol. 89 (2008) 169-175. doi:10.1016/j.fuproc.2007.09.002.

[52] M.R. Wu, D.L. Schott, G. Lodewijks, Physical properties of solid biomass, Biomass and Bioenergy. 35 (2011) 2093-2105. doi:10.1016/j.biombioe.2011.02.020. 